\title{
Prediction of the risk of cardiovascular mortality using a score that includes glucose as a risk factor. The DECODE Study
}

\author{
The DECODE Study Group • on behalf of the European Diabetes Epidemiology Group
}

\begin{abstract}
Aims/hypothesis. Risk scores have been developed to predict cardiovascular or coronary risk, and while most have included diabetes as a risk factor, none have included lower glucose concentrations, either at fasting or following a 2 -h oral glucose tolerance test. This article develops 5- and 10-year risk scores for cardiovascular mortality that include glucose concentrations as well as known diabetes status.

Methods. Data is from the DECODE cohort: 16,506 men and 8,907 women from 14 European studies. The risk factors studied were as follows: age, fasting and 2-h glucose (including cases of known diabetes), fasting glucose alone (including cases of known diabetes), cholesterol, smoking status, systolic blood pressure and BMI. For an absolute risk score the 1995 countryand sex-specific cardiovascular death rates were used. Results. In men, for both 5- and 10-year cardiovascular mortality, after adjusting for age and study centre,
\end{abstract}

all studied risk factors, except BMI, were significantly associated with cardiovascular mortality $(p<0.05)$. These results were unchanged in multivariate models with all factors included. In women, after adjusting for age and centre, glucose categories, systolic blood pressure and BMI were predictive of 5-year cardiovascular mortality. With all factors in the model, only age and glucose categories were predictive. In terms of 10-year cardiovascular mortality, smoking status and blood pressures were also predictive in the women. For men and women, the same scores were used for the risk factors, except for age and glucose categories where the hazard ratios differed significantly. Conclusions/interpretation. Including glucose concentrations as well as diabetic status provides quantitative information on cardiovascular risk prediction.

Keywords Cardiovascular disease $\cdot$ Diabetes . Epidemiology $\cdot$ Glucose $\cdot$ Risk factors $\cdot$ Risk score
Received: 15 April 2004 / Accepted: 19 July 2004

Published online: 15 December 2004

(C) Springer-Verlag 2004

Corresponding author of the DECODE Insulin Study Group:

B. Balkau

IINSERM U258-IFR69,

16 Avenue Paul Vaillant Couturier,

94807 Villejuif cedex, France,

Phone: +33-1-4559516, Fax: +33-1-47269454

e-mail: balkau@vjf.inserm.fr

Abbreviations: FPG, fasting plasma glucose .

2hPG, 2-h plasma glucose

\section{Introduction}

The prevention of cardiovascular diseases is now targeted for the reduction of the overall absolute risk of the disease $[1,2,3,4]$, taking into account a number of risk factors. Various risk scores have been developed to estimate the risk of a coronary or a cardiovascular event (or mortality) within a given time frame in those without cardiovascular disease at baseline. The original risk scores were developed from the Framingham Study and they have been updated several times $[5,6,7,8]$. The first score included the major risk factors that had been identified at the time: sex, age, systolic blood pressure, total cholesterol, cigarette use, diabetes and left ventricular hypertrophy (from an 


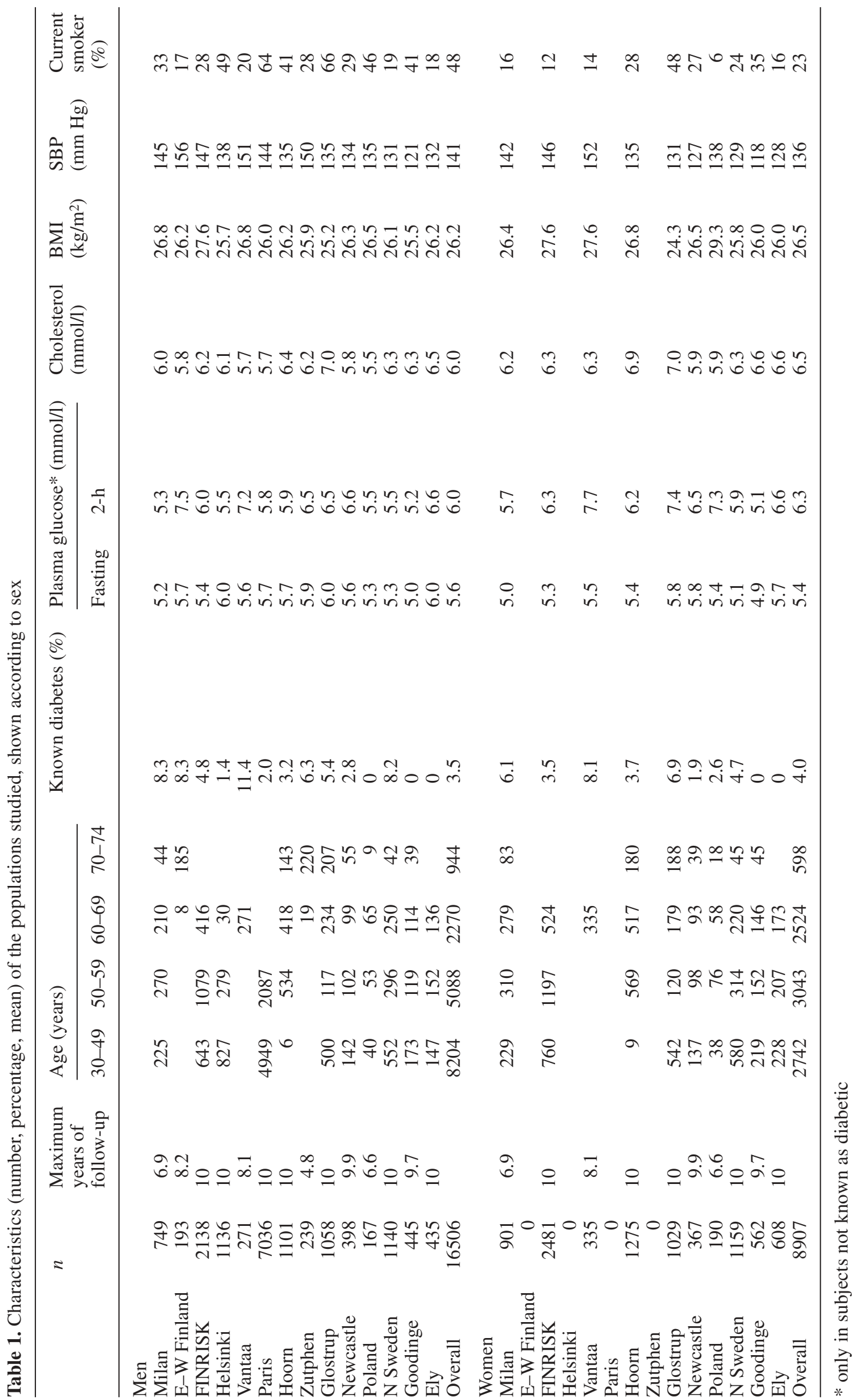


ECG) [5]. The most recent score from the Framingham Study [8] used age, categories of blood pressure, cigarette use, total and HDL cholesterol, and diabetes. A number of other authors have also developed scores or predictions for cardiovascular morbidity or mortality $[9,10,11,12,13,14,15,16]$. In 2003 the European SCORE project published their risk score based on pooled data from more than 200,000 men and women $[1,17]$. The Framingham and other risk scores have been tested in different populations $[11,15,18,19$, $20,21,22,23,24]$. The general conclusion from the comparative studies is that while the absolute risk may differ from population to population, the risk ranking provided by these scores is consistent over populations.

Diabetes has long been recognised as a major cardiovascular risk factor, and diabetic subjects have a risk of early death, in particular from cardiovascular disease, that is at least two times higher than that of subjects with normal glucose concentrations [25, 26]. Diabetic status has been included in almost all risk equations, although in the SCORE project it was not included as it was not uniformly collected in the participating studies. Results from a number of cohort studies, in particular from the DECODE Study, indicate that glucose concentrations, both fasting and $2 \mathrm{~h}$ post-challenge, that are below the threshold levels used for the diagnosis of diabetes are also risk factors for cardiovascular mortality $[25,26,27,28,29,30$, $31]$.

We used the large European DECODE cohort to develop risk scores for cardiovascular mortality over 5-year and 10-year follow-up periods. In addition to the classical cardiovascular risk factors we included glucose concentrations and known diabetic status in this score. We developed a score for absolute risk based on country-specific cardiovascular disease death rates for 1995.

\section{Subjects and methods}

Study population. The methods used to recruit the participants in the DECODE Study have been reported in our previous publications [25, 26, 31]. Briefly, data on mortality from population-based studies or large studies in occupational groups in Europe, that included glucose concentrations at fasting and $2 \mathrm{~h}$ after a 75-g OGTT, were collated and analysed in the Diabetes and Genetic Epidemiology Unit of the National Public Health Institute in Helsinki, Finland.

A total of 14 cohorts provided data on cardiovascular mortality and on the following cardiovascular risk factors: age, smoking habits, arterial blood pressures, total cholesterol concentration and BMI as well as fasting and 2-h glucose concentrations and diabetic status. Other risk factors such as HDL cholesterol, triglycerides and waist circumference were not available in all of the cohorts. Subjects were followed up over a minimum of 4.8 years for mortality, and a number of studies had more than 10 years of follow-up.

Ethical standards relevant at the time of the studies were adhered to.
Table 2. Numbers of cardiovascular deaths at 5 and 10 years, shown according to population and sex

\begin{tabular}{|c|c|c|c|c|c|}
\hline & \multirow[t]{2}{*}{$n$} & \multicolumn{2}{|c|}{5 years } & \multicolumn{2}{|c|}{10 years } \\
\hline & & $n$ & $\%$ & $n$ & $\%$ \\
\hline \multicolumn{6}{|l|}{ Men } \\
\hline Milan & 749 & 9 & 1.2 & 16 & 2.1 \\
\hline E-W Finland & 193 & 22 & 11.4 & 38 & 19.7 \\
\hline FINRISK & 2138 & 64 & 3.0 & 132 & 6.2 \\
\hline Helsinki & 1136 & 18 & 1.6 & 46 & 4.0 \\
\hline Vantaa & 271 & 10 & 3.7 & 21 & 7.7 \\
\hline Paris & 7036 & 20 & 0.3 & 77 & 1.1 \\
\hline Hoorn & 1101 & 25 & 2.3 & 69 & 6.3 \\
\hline Zutphen & 239 & 26 & 10.9 & 26 & 10.9 \\
\hline Glostrup & 1058 & 35 & 3.3 & 87 & 8.2 \\
\hline Newcastle & 398 & 15 & 3.8 & 27 & 6.8 \\
\hline Poland & 167 & 12 & 7.2 & 13 & 7.8 \\
\hline N Sweden & 1140 & 22 & 1.9 & 40 & 3.5 \\
\hline Goodinge & 445 & 21 & 4.7 & 28 & 6.3 \\
\hline Ely & 435 & 2 & 0.5 & 12 & 2.8 \\
\hline Overall & 16506 & 301 & 1.8 & 632 & 3.8 \\
\hline \multicolumn{6}{|l|}{ Women } \\
\hline Milan & 901 & 3 & 0.3 & 5 & 0.6 \\
\hline E-W Finland & 0 & & & & \\
\hline FINRISK & 2481 & 9 & 0.4 & 36 & 1.5 \\
\hline Helsinki & 0 & & & & \\
\hline Vantaa & 335 & 2 & 0.6 & 9 & 2.7 \\
\hline Paris & 0 & & & & \\
\hline Hoorn & 1275 & 16 & 1.3 & 33 & 2.6 \\
\hline Zutphen & 0 & & & & \\
\hline Glostrup & 1029 & 9 & 0.9 & 37 & 3.6 \\
\hline Newcastle & 367 & 1 & 0.3 & 8 & 2.2 \\
\hline Poland & 190 & 1 & 0.5 & 2 & 1.1 \\
\hline N Sweden & 1159 & 9 & 0.8 & 12 & 1.0 \\
\hline Goodinge & 562 & 5 & 0.9 & 12 & 2.1 \\
\hline Ely & 608 & 1 & 0.2 & 5 & 0.8 \\
\hline Overall & 8907 & 56 & 0.6 & 159 & 1.8 \\
\hline
\end{tabular}

Vital status. Vital status was followed up in the subjects who attended the baseline examination. Subjects who emigrated, for whom vital status could not be confirmed, were censored at the time of emigration. The follow-up was almost complete, from $95 \%$ in the Paris Prospective Study to $100 \%$ in most of the other studies, and the maximum length of follow-up for each study is given in Table 1 .

Fatal events were classified using the International Classification of Diseases: cardiovascular diseases were defined by codes 401 to 448 of the Eighth or Ninth Revisions and codes I10 to I79 for the Tenth Revision [32, 33]. Causes of death were obtained from death certificates or were arbitrated by an independent medical panel.

Statistical analysis. Before analysis, if glucose concentrations were not measured in plasma, they were transformed into plasma glucose concentrations, as already documented in other DECODE Study publications [34]. Subjects were classified according to age, fasting and 2-h plasma glucose (FPG and $2 \mathrm{hPG}$ ) concentrations, fasting plasma glucose (FPG) concentration, smoking habits, systolic blood pressures, total cholesterol concentration, and BMI (Table 2). In particular the FPG and $2 \mathrm{hPG}$ concentrations have been grouped into four classes according to WHO recommendations [35]: (i) normal fasting glucose and normal glucose tolerance (FPG $<6.1 \mathrm{mmol} / \mathrm{l}$ and 


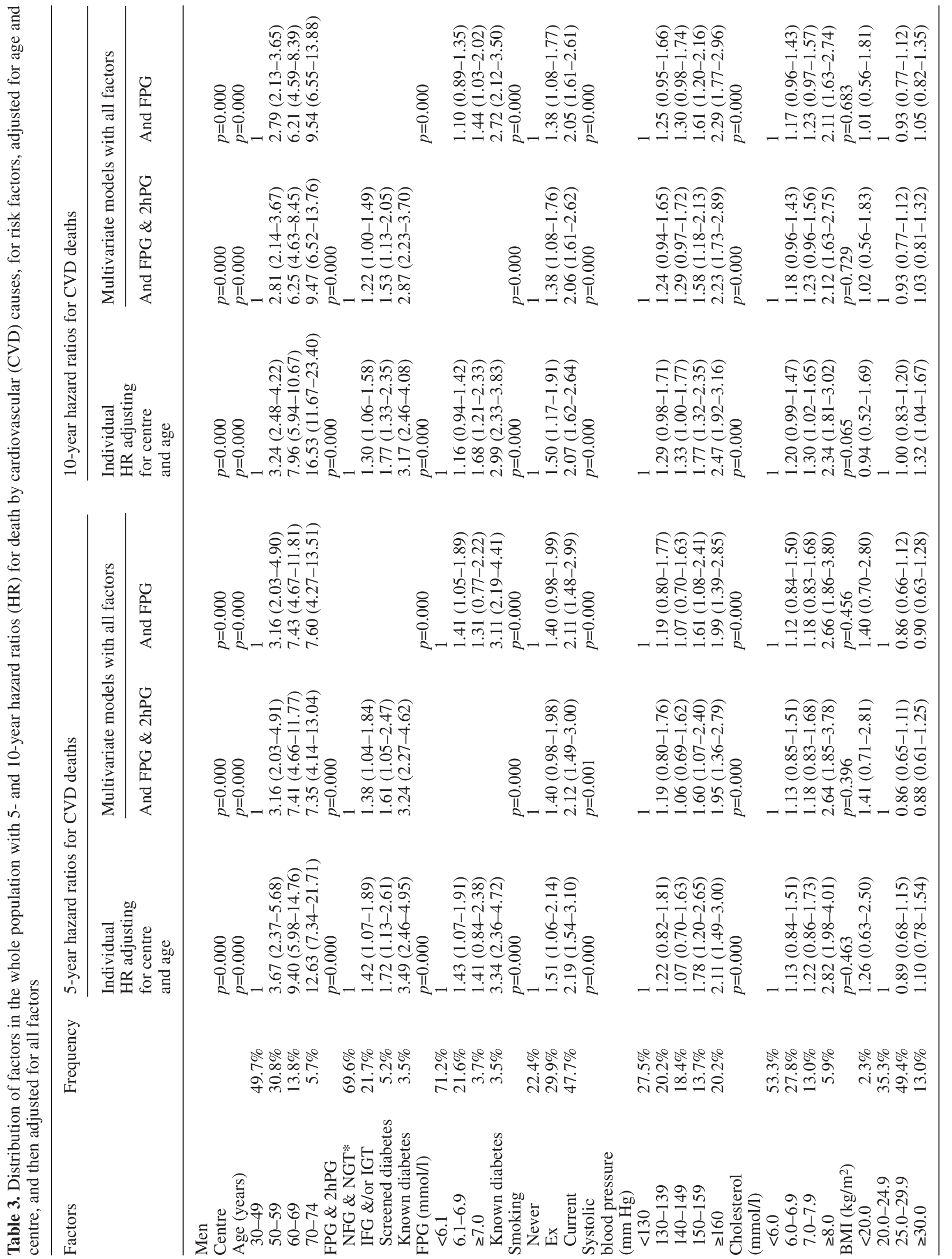




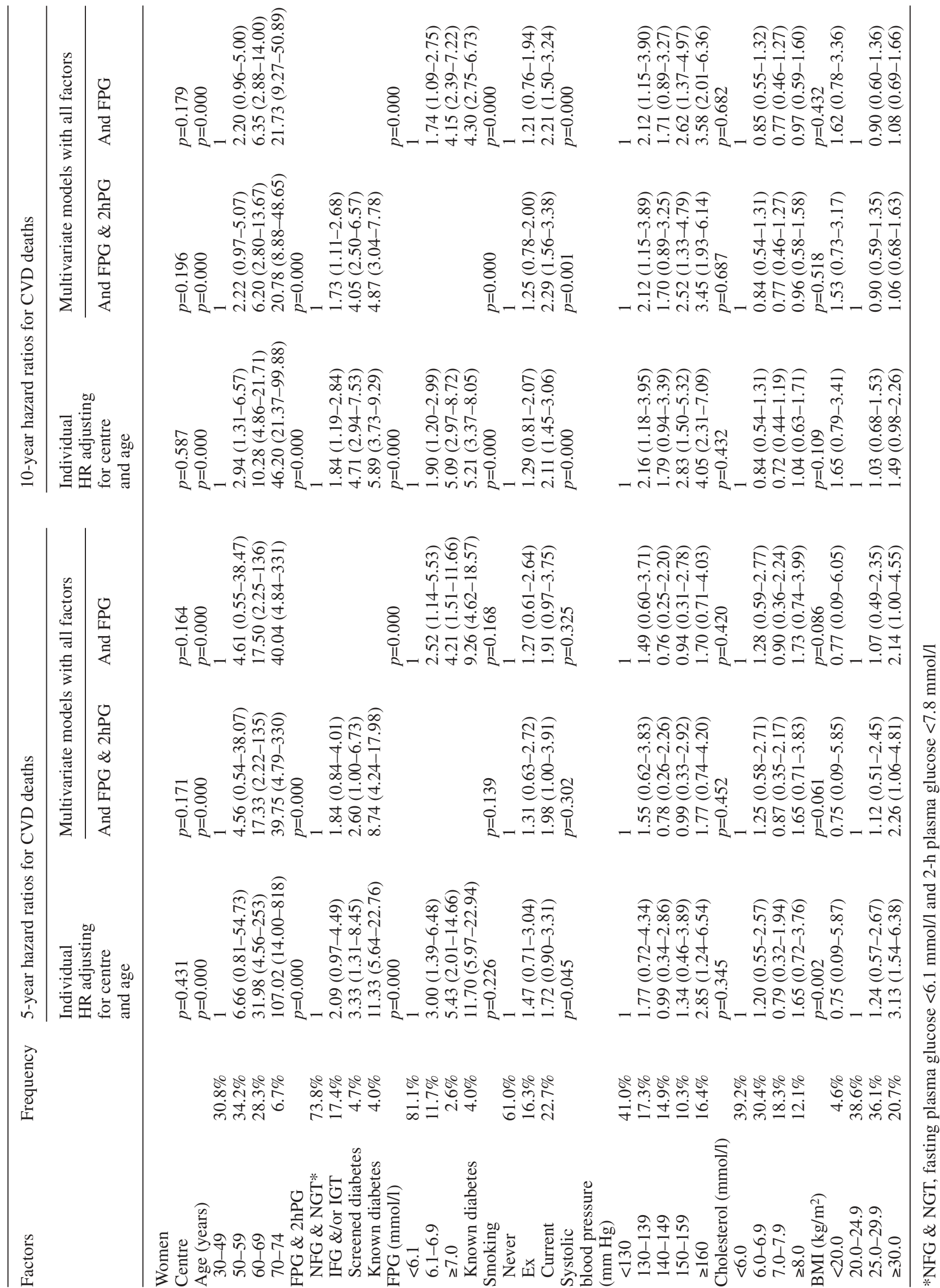


2hPG $<7.8 \mathrm{mmol} / \mathrm{l}$ ); (ii) IGT and/or IFG (impaired glucose regulation which includes IGT and IFG, non-diabetic subjects with $\mathrm{FPG} \geq 6.1$ but $<7.0 \mathrm{mmol} / \mathrm{l}$ and/or $2 \mathrm{hPG} \geq 7.8$ but $<11.1 \mathrm{mmol} / \mathrm{l}$ ); (iii) screened diabetes with $\mathrm{FPG} \geq 7.0 \mathrm{mmol} / \mathrm{l}$ and/or $2 \mathrm{hPG} \geq 11.1 \mathrm{mmol} / \mathrm{l}$ and no previous history of diabetes; and (iv) known diabetes (diabetes diagnosed before the baseline examinations).

The glycaemic status according to the FPG concentration is also grouped into four categories: (i) normal fasting glucose (FPG <6.1 mmol/l); (ii) IFG $(6.1 \geq \mathrm{FPG}<7.0 \mathrm{mmol} / \mathrm{l})$; (iii) screened diabetes (diagnosed by a fasting hyperglycaemia, FPG $\geq 7.0 \mathrm{mmol} / \mathrm{l}$ and no previous history of diabetes); and (iv) known diabetes (diagnosed before the baseline examinations).

The hazard ratios for cardiovascular mortality were estimated for men and women separately, using Cox proportional hazards models. All models were adjusted for age (in age categories) and for study centre to allow for the fact that the absolute risk varies from one population to another [11, 17, 18, 19, $20,21,22,23,24]$. All factors were included as categories in the risk score to allow for possible non-linear effects of the factors and so that a risk score can be evaluated for a given individual by simply summing scores corresponding with the categories for each factor.

The hazard ratios associated with each factor were estimated, and then two multivariate models were determined including all factors, the first with categories for FPG and $2 \mathrm{hPG}$ and the second with only FPG categories, to correspond with the two situations where an OGTT is or is not available. The log likelihood ratio test was used to test whether the risk factors had significantly different effects in men and women, in multivariate models, with all factors included except BMI, which was not a significant predictor in multivariate models.

We gave a risk score for each category of each factor. These scores are the beta coefficients, from the Cox proportional hazards model, multiplied by 10 and rounded to the closest integer. For the two models, the first with FPG and 2hPG and the second with only FPG categories, the beta coefficients for the other parameters were almost identical, and for simplicity have been averaged in the final risk score. The risk score for an individual is obtained by summing the scores for the appropriate level of each of the risk factors. This simple, easily calculated score is a relative risk score for a given population.

To estimate an absolute risk of cardiovascular mortality, based on the 1995 mortality statistics, we used the Italian cohort from Milan as a reference group. This particular cohort was chosen because it included both men and women, and had subjects in all age categories studied. In this cohort the probability of a cardiovascular death is given by the Cox model by $[1-\mathrm{S} \exp (\mathrm{R} / 10)]: \mathrm{S}$ is the survival probability, estimated for either the 5- or 10-year follow-up, and it is averaged over the two models, the first with FPG and 2hPG and the second with FPG alone; $\mathrm{R}$ is the risk score, calculated as above, for either the 5- or 10-year follow-up period. As cardiovascular disease mortality differs between countries, we use the WHO causes of death statistics to calibrate the absolute risk for other countries, with the assumption that the cardiovascular mortality experience in the Italian cohort in the DECODE Study is representative of the country as a whole. The 1995 mortality statistics available from the WHO web site [36] enabled us to determine a multiplying factor for country-specific cardiovascular disease mortality in relation to Italian cardiovascular disease mortality. We derived sex-specific multiplying factors (M) using the average value of the ratios of the 1995 cardiovascular mortality (ICD9 codes 401-448 [32]), in 5-year age classes, in particular countries with respect to Italy, over the age range of 35 to 79 years. The complete equation for predicting death is then $\mathrm{M}[1-\mathrm{S} \exp (\mathrm{R} / 10)]$.
SPSS for Windows 11.0 was used for statistical analysis. A $p$ value of less than 0.05 was considered statistically significant, although exact $p$ values are reported.

\section{Results}

We studied 16,506 men and 8,907 women aged 30 to 74 years (Table 1 ); four of the 14 studies only included men. The numbers of subjects in the individual cohorts were quite diverse, and the complete age range was covered in seven of the 14 studies. Almost half of the men and one-third of the women were under 50 years of age. Close to $70 \%$ of the population had normal glucose levels, $4 \%$ had known diabetes and $5 \%$ were screened as diabetic. Three of the studies did not include subjects who were known to have diabetes. For the other cardiovascular risk factors, in men almost 50\% smoked, 20\% had hypertension (systolic blood pressure $\geq 160 \mathrm{~mm} \mathrm{Hg}$ ), $20 \%$ had high cholesterol concentrations $(\geq 7.0 \mathrm{mmol} / \mathrm{l})$, and $13 \%$ were obese $\left(\mathrm{BMI} \geq 30 \mathrm{~kg} / \mathrm{m}^{2}\right)$. In women, $23 \%$ smoked, $16 \%$ had hypertension, $30 \%$ had high cholesterol and $21 \%$ were obese.

From the pooled cohort, $301(1.8 \%)$ of the men and $56(0.6 \%)$ of the women died from cardiovascular causes during 5 years of follow-up (Table 2); over 10 years, there were $632(3.8 \%)$ and $159(1.8 \%)$ cardiovascular deaths respectively.

Over 5 years, the risk of cardiovascular mortality differed between centres for the men, after adjusting for age class (Table 3). Among the men, after adjusting for age and study centre, glucose concentrations, smoking, systolic blood pressure and cholesterol concentrations were significant predictors of 5-year cardiovascular mortality, but BMI was not a predictor. These factors all remained predictive when they were entered together into a multivariate model. In women, after age and centre adjustment, only glucose concentrations, systolic blood pressure and BMI were significant predictors of cardiovascular mortality; however, when all factors were entered into a model, only the glucose concentrations and age were predictive. There were significant differences in the effects on 5-year cardiovascular mortality between sex and age $(p<0.005)$ and between sex and glucose concentrations $(p<0.05$ and $p<0.005$ for the FPG and $2 \mathrm{hPG}$ and the FPG categories respectively).

Over the 10-year period, after adjusting for age and centre, BMI was not predictive of cardiovascular mortality, either in men or in women. In both sexes, glucose concentrations, smoking and systolic blood pressure were predictive, whereas the cholesterol concentration also added to the prediction of fatal cardiovascular risk in men but not in women. These results did not change when all factors were entered into a multivariate model. Again, only the effects of age and glucose levels, whether by FPG and 2hPG or by FPG 
Table 4. Risk score coefficients for cardiovascular mortality, over 5 and 10 years of follow-up. For a given individual these scores should be added, and either the FPG and 2hPG or the FPG scores should be chosen

\begin{tabular}{|c|c|c|c|c|}
\hline \multirow[t]{2}{*}{ Years of follow-up } & \multicolumn{2}{|c|}{5 years } & \multicolumn{2}{|c|}{10 years } \\
\hline & $\begin{array}{l}\text { Men } \\
0\end{array}$ & $\begin{array}{l}\text { Women } \\
-28\end{array}$ & $\begin{array}{l}\text { Men } \\
0\end{array}$ & $\begin{array}{l}\text { Women } \\
-15\end{array}$ \\
\hline \multicolumn{5}{|l|}{ Age (years) } \\
\hline $30-49$ & 0 & 0 & 0 & 0 \\
\hline $50-59$ & 11 & 16 & 10 & 8 \\
\hline $60-69$ & 20 & 29 & 18 & 18 \\
\hline $70-74$ & 21 & 35 & 22 & 28 \\
\hline \multicolumn{5}{|l|}{ FPG \& 2hPG } \\
\hline NFG \& NGT & 0 & 0 & 0 & 0 \\
\hline IFG \&/or IGT & 3 & 7 & 2 & 5 \\
\hline Screened diabetes & 5 & 11 & 4 & 14 \\
\hline Known diabetes & 12 & 22 & 10 & 16 \\
\hline \multicolumn{5}{|l|}{ FPG (mmol/l) } \\
\hline$<6.1$ & 0 & 0 & 0 & 0 \\
\hline $6.1-6.9$ & 3 & 10 & 1 & 6 \\
\hline$\geq 7.0$ & 2 & 16 & 4 & 14 \\
\hline Known diabetes & 11 & 23 & 10 & 15 \\
\hline \multicolumn{5}{|l|}{ Smoking } \\
\hline Never & 0 & 0 & & \\
\hline Ex & 3 & 3 & & \\
\hline Current & 7 & 7 & & \\
\hline \multicolumn{5}{|c|}{$\begin{array}{l}\text { Systolic blood pressure } \\
\text { (mm Hg) }\end{array}$} \\
\hline$<130$ & 0 & 0 & & \\
\hline $130-139$ & 2 & 3 & & \\
\hline $140-149$ & 0 & 3 & & \\
\hline $150-159$ & 4 & 5 & & \\
\hline$\geq 160$ & 7 & 9 & & \\
\hline \multicolumn{5}{|l|}{ Cholesterol (mmol/l) } \\
\hline$<6.0$ & 0 & 0 & & \\
\hline $6.0-6.9$ & 1 & 1 & & \\
\hline 7.0-7.9 & 1 & 1 & & \\
\hline$\geq 8.0$ & 9 & 6 & & \\
\hline
\end{tabular}

* NFG \& NGT, fasting plasma glucose $<6.1 \mathrm{mmol} / \mathrm{l}$ and 2-h plasma glucose $<7.8 \mathrm{mmol} / \mathrm{l}$

classes, differed between the sexes $(p<0.001$ for age, $p<0.005$ and $p<0.005$ for glucose categories respectively).

Sex-specific scores are given for age and for glucose concentrations, and the other scores are common for men and women (Table 4). BMI has not been included in the final risk score as it was not a significant predictor of cardiovascular mortality in the multivariate models. From log likelihood ratio tests, the glucose factors improved the prediction $(p<0.001)$ for cardiovascular disease when glucose was either in the form of FPG and 2hPG classes or as FPG classes, both in men and in women.

The sex- and country-specific multiplying factor (M) and the cumulated survival probabilities (S) are given in Table 5 to enable the calculation of the abso-
Table 5. Multiplying factors (M) and survival factors (S) to obtain the absolute risk of cardiovascular mortality for an individual from the risk score using the equation $M(1-S \exp ($ risk score/10))

\begin{tabular}{llll}
\hline Multiplying factors & Country & Men & Women \\
\cline { 2 - 4 } & France & 0.83 & 0.70 \\
& Italy & 1 & 1 \\
& Sweden & 1.09 & 1.00 \\
& The Netherlands & 1.17 & 1.29 \\
& UK & 1.43 & 1.46 \\
& Finland & 1.67 & 1.25 \\
& Poland & 2.87 & 2.61 \\
Survival factors & Follow-up time & & \\
& 5-years & & 0.998873 \\
& 10-years & & 0.997508 \\
\hline
\end{tabular}

Table 6. The estimated absolute risk (\%) of cardiovascular mortality in men and women from Italy, aged 55 years, smokers, with systolic blood pressure of $145 \mathrm{~mm} \mathrm{Hg}$ and cholesterol concentration of $6.5 \mathrm{mmol} / \mathrm{l}$, shown according to glucose tolerance status

\begin{tabular}{|c|c|c|c|c|}
\hline & \multicolumn{2}{|c|}{5 years } & \multicolumn{2}{|c|}{10 years } \\
\hline & Men & Women & Men & Women \\
\hline NGT & $0.8 \%$ & $0.1 \%$ & $2.0 \%$ & $0.4 \%$ \\
\hline IFG & $1.0 \%$ & $0.2 \%$ & $2.2 \%$ & $0.7 \%$ \\
\hline $\begin{array}{l}\text { Diabetic on fasting } \\
\text { glucose }\end{array}$ & $0.9 \%$ & $0.4 \%$ & $3.0 \%$ & $1.5 \%$ \\
\hline IFG \&/or IGT & $1.0 \%$ & $0.2 \%$ & $2.5 \%$ & $0.6 \%$ \\
\hline $\begin{array}{l}\text { Diabetic on fasting } \\
\text { \&/or 2-h glucose }\end{array}$ & $1.4 \%$ & $0.2 \%$ & $3.0 \%$ & $1.5 \%$ \\
\hline Known diabetic & $2.4 \%$ & $0.8 \%$ & $5.4 \%$ & $1.7 \%$ \\
\hline
\end{tabular}

lute risk of cardiovascular death within the given 5- or 10 -year time periods: $\mathrm{M} \times[1-\mathrm{S} \exp (\mathrm{R} / 10)]$, using the risk score R.

As an example of using this risk score, we have estimated in Table 6 the 5- and 10-year risk of cardiovascular mortality for an Italian man and for an Italian woman aged 55 years, who smoked, had a systolic blood pressure of $145 \mathrm{~mm} \mathrm{Hg}$ and a cholesterol concentration of $6.5 \mathrm{mmol} / \mathrm{l}$ according to different glucose categories. The 5-year risk for cardiovascular mortality was under $1 \%$, except in the diabetic men. At 10 years of follow-up there was a gradual increase as the glucose intolerance worsened, which was especially marked in women.

\section{Discussion}

Results from the DECODE Study. While many of the cardiovascular risk scores have included diabetes, this is the first to include non-diabetic glucose concentrations. Glucose concentrations below the diabetic level had not been recognised as a risk factor for premature 
death. The DECODE cohort has demonstrated that high plasma glucose is an independent risk factor for cardiovascular diseases and mortality [25, 26, 31, 34] and this has been supported by other studies $[29,30]$. The large DECODE database enabled risk scores to be estimated, and a score could be given for a 5-year follow-up of cardiovascular mortality, in men as well as in women, where the event rate was low.

As expected, age was always the strongest risk factor for cardiovascular mortality. At both 5 and 10 years of follow-up of the DECODE cohort, glucose concentrations were always predictive of cardiovascular mortality. For the other risk factors studied, smoking was always predictive of mortality, except for the 5-year cardiovascular mortality in women, where the risk was a little lower, but not statistically different, compared with that in men (cardiovascular mortality hazard ratios for current smokers of 2.19 [95\% CI: 1.54-3.10] for men and 1.72 [0.90-3.31] for women). Systolic blood pressure was always predictive of cardiovascular mortality, except over the 5-year period in women. For women, cholesterol was never predictive, but in men it was predictive at both 5 and 10 years. In fact, the effects of cholesterol and systolic blood pressure did not differ significantly between men and women. The lack of significant results in women is due to lack of power, as there were fewer cardiovascular deaths than in the men. In multivariate models, BMI was never predictive of cardiovascular mortality, although it came close in the women over 5 years of follow-up. Obesity has an impact through its association with the other risk factors.

The risk associated with the glucose concentrations was not just due to the diabetic subjects. Almost always, all of the hyperglycaemic classes had significantly higher risks than the reference group. Men with known diabetes had a two-fold higher cardiovascular mortality in comparison with the screened diabetic men, for both 5 and 10 years of follow-up; the cardiovascular risk in screened diabetic men was only slightly higher than that associated with the prediabetic classes. The hazard ratios for the diabetic or prediabetic states were much higher in the women than in the men, making the inclusion of glucose in a risk score very important for women. While the hazard ratios increased over the glucose classes, at 5 years, the risk was much higher for the women with known diabetes than for the women with screened diabetes, but at 10 years, the risks were almost identical. The risk scores indicate clearly that age and glucose concentrations (in particular diabetes) strongly predict cardiovascular mortality. It is of note that in women, the prediabetic states carry a similar cardiovascular risk to current smoking.

The hazard ratios associated with the risk factors decreased slightly as the length of follow-up increased, except in the case of systolic blood pressure.
As life expectancy and the risk of cardiovascular mortality differs between regions, countries and within countries, the risk score ranks individuals, within a given context. We also provide a method of obtaining an absolute risk score for a country, calibrated using the WHO mortality statistics.

Comparison with other risk scores. It may be inadvisable to compare the actual coefficients from the factors in the models derived from different studies, as these factors may intercorrelate differently in different populations. The aim of these risk score functions is to predict the risk, and it is of less importance to interpret the individual factors. However, one study has compared the individual hazard functions for coronary events in eight male populations, and five female populations [19]; they found some similarities and some differences between ethnic groups for the major cardiovascular risk factors.

For the Framingham score [8], the actual weights for each of the factor categories are similar to those in our study, but both total and HDL cholesterol are included in the Framingham model, and we are only able to include total cholesterol. Further, as we include glucose concentrations and the Framingham score does not, the two risk functions are not really comparable. Additionally, our score is for cardiovascular mortality, whereas the Framingham score is for coronary events.

Risk scores for cardiovascular, coronary, cerebrovascular and all-cause mortality were derived from a meta-analysis of 47,000 adults with raised blood pressure, treated in eight clinical trials [12]. Follow-up was from 2.0 to 6.9 years, with a mean follow-up of 5.2 years. The risk factors were used as continuous variables (age, cholesterol concentration, systolic blood pressure) in a Cox proportional hazards model. They found that these continuous factors were linear in predicting mortality, a result different from in the Framingham study [8] where for women, age was better modelled by both linear and squared terms. In the final risk score, these continuous variables were categorised to provide a score with integers which is easily calculable by a physician. Initially they used 16 risk factors, but as four were not significant in the multivariate models, 12 factors remained, and after investigating interactions among them, five significant interaction terms were retained in the cardiovascular model. With age there were significant three-way interactions with smoking and sex and there were two-way interactions between sex and each of diabetes, cholesterol concentrations and smoking status. In contrast, we found that only age and glucose concentrations had differing effects on cardiovascular mortality in men and women. This is in keeping with previous findings, with a lower risk in women than in men in middle age, but similar risks between the sexes in the elderly. Further, women who are diabetic lose their 
protective advantage as we have already shown in the DECODE Study [34].

Another risk score comes from the PROCAM study [13], but this is restricted to the 10-year risk of a myocardial infarction in men. This score includes both LDL and HDL cholesterol and triglycerides, but not total cholesterol or glucose concentrations.

The European SCORE project provides the most recent risk score [17], a 10-year risk score for both coronary and non-coronary cardiovascular mortality based on the classic risk factors: sex, age, systolic blood pressure, smoking and either total cholesterol or total : HDL cholesterol. The use of the cardiovascular risk charts is recommended in the European Guidelines on Cardiovascular Disease and Prevention in Clinical Practice [1]. Diabetes was not included in the SCORE risk score because of lack of comparable data in the individual studies, but in the European recommendations, separate treatment thresholds are given for diabetic patients for both cholesterol and blood pressure.

The need to include other cardiovascular risk factors in the risk score has been investigated in the ARIC study [16]. They developed a predictive score using the basic risk factors smoking, diabetes, HDL cholesterol, total cholesterol, systolic blood pressure (including medication), and then investigated the merit of including various other risk factors, using as a criterion an increase in the area under the ROC curve to predict an incident event. Glucose concentrations were not studied. They concluded that there was no single risk factor (either a basic or a new risk factor) that "provided a large increase in predictivity" besides systolic blood pressure. When the 10-year predicted risks were compared between (i) the basic model with traditional risk factors and (ii) the model with all considered risk factors, there were more events predicted in the last decile group of the latter risk score, enabling high-risk subjects to be better identified.

The UKPDS risk engine has been developed for diabetic patients, for both coronary heart disease and for stroke $[37,38]$. Some of the subjects included in the UKPDS had a FPG of only $6 \mathrm{mmol} / \mathrm{l}$ at inclusion, so are comparable to the hyperglycaemic subjects in our study. While the initial glucose levels were not used in this score, $\mathrm{HbA}_{1} \mathrm{c}$ was a significant risk factor for fatal and non-fatal myocardial infarction or sudden death, corroborating our results with subjects classified as screened diabetic and IFG or IGT.

Limitations of this study. Our study has a number of limitations. The first is that there was not a homogeneous protocol for data collection, and each centre measured both physical and laboratory measures according to their own protocols. Glucose was measured not only in different laboratories, but with differing assay methods and different forms of blood samples, but concentrations have been transformed so that they correspond with plasma glucose [34]. The cardiovas- cular endpoints are also likely to be affected by the individual centre and country practices of classification, despite the common use of the International Classification of Diseases $[34,35]$. These study differences would all serve to lower the precision of the data, and so make our statistical results less significant than if a common standardised protocol had been used.

The 14 cohorts from which we draw our results are quite diverse. We studied the effect of the individual risk factors in each of the cohorts, and found that they had a consistent effect on cardiovascular mortality, but the relations were often not significant in individual cohorts because of their small size and limited number of events.

One limitation for the comparison of this score with scores developed from other studies is that we have no knowledge of whether the subjects already had cardiovascular disease at baseline. Usually the relations between risk factors and events are weaker after cardiovascular disease is manifest, so our results would tend to be less significant because of this. Most other scores have been based on subjects free of cardiovascular disease. An advantage is that our score can be applied to all subjects, regardless of their previous history of cardiovascular disease.

While we added a new factor, glucose concentrations, to this risk score, we are not able to include HDL cholesterol or triglyceride concentrations [8, 13], or waist circumference or waist hip ratio [16] as these variables were not available for all of the DECODE cohorts. No doubt other risk scores, such as the risk score in the ARIC study [16], will be developed to include parameters that have more recently been shown to be predictive of cardiovascular mortality, such as C-reactive protein, fibrinogen and other markers of inflammation, microalbuminuria and numerous other factors $[39,40,41]$.

Another limitation is that while all cohorts have a follow-up of almost 5 years, the 10-year follow-up is available in seven of the 14 cohorts, with 8 or more years in 11 of the 14 studies. These seven cohorts with a complete 10-year follow-up, provide $85 \%$ of the data in the men and $74 \%$ in the women. Further, two of the English cohorts, which total under $10 \%$ of the subjects in the study, did not include known diabetic subjects in their data collection.

Conclusions. For diabetic patients, a recent article [42] indicated that such cardiovascular risk scores have a role in clinical practice. In an outpatients' clinic, the calculation of a risk score led to an increase in the prescription of risk-modifying drugs, but appropriately, only for the patients at higher risk. Glucose concentrations, whether we combine fasting and 2-h glucose concentrations or whether we use fasting glucose alone, play a role in predicting cardiovascular mortality in subjects with hyperglycaemia. In particular they have an important role in predicting the risk in wom- 
en. This score now needs to be validated in other populations.

Acknowledgements. This analysis has been carried out with the help of grants from Novartis Pharma (Basel, Switzerland), AstraZeneca R\&D (Mölndal, Sweden) and the Academy of Finland (grants 46558, 76502, 77618, 204274, 205657). The DECODE Study was initially funded by Novo Nordisk (Bagsvaerd, Denmark).

Organisation. The DECODE Study (Diabetes Epidemiology: Collaborative Analysis of Diagnostic Criteria in Europe) was undertaken in 1997 upon the initiative of the European Diabetes Epidemiology Group (Chairman: K. Borch-Johnsen; Vicechairman: A. Neil; Secretary: B. Balkau).

Investigators and study centres included in this analysis:

Denmark. Glostrup Population Studies (three cohorts): S. Larsen, K. Borch-Johnsen, Centre for Preventive Medicine, Glostrup.

Finland. East-West Finland Study: A. Nissinen, J. Pekkanen, J. Tuomilehto, Department of Epidemiology and Health Promotion, National Public Health Institute, Helsinki.

FIN-MONICA: J. Tuomilehto, P. Jousilahti, J. Lindström, Department of Epidemiology and Health Promotion, National Public Health Institute, Helsinki.

Helsinki Policemen Study: M. Pyörälä, K. Pyörälä, Department of Medicine, University of Kuopio.

Vantaa Study: R. Tilvis, Division of Geriatrics, Department of Medicine, University of Helsinki, Helsinki.

France. Paris Prospective Study: B. Balkau, E. Eschwège, INSERM U258-IFR69, Paris.

Italy. Cremona Study: G. Gallus, M. P. Garancini, Institute of Medical Statistics-University of Milan and Epidemiology Unit, S. Raffaele Institute, Milan.

The Netherlands. The Hoorn Study: L. Bouter, J. Dekker, R. Heine, G. Nijpels, C. Stehouwer, Institute for Research in Extramural Medicine, Vrije Universiteit Medical Center, Amsterdam.

The Zutphen Elderly Study: E. Feskens, D. Kromhout, Institute of Public Health, Bilthoven.

Poland. POL-MONICA Study (Krakow): A. Pajak, Department of Clinical Epidemiology and Population Studies, Institute of Public Health, Collegium Medicum, Jagiellonian University, Krakow.

Sweden. The Northern Sweden MONICA Study (three cohorts): M. Eliasson, B. Stegmayr, V. Lundberg. Department of Medicine, University of Umeå.

United Kingdom. Isle of Ely Diabetes Project: N. Wareham, Department of Public Health and Primary Care, University of Cambridge.

Newcastle Heart Project: N. Unwin, N. Ahmad, G. Alberti, L. Hayes. Department of Medicine and Epidemiology and Public Health, University of Newcastle, Newcastle.

The Goodinge Study: J. Yudkin, M. Gould, A. Haines, R. Morris. Centre for Diabetes and Cardiovascular Risk and Department of Primary Health Care, University College London Medical School.

Secretariat: K. Borch-Johnsen, Steno Diabetes Center, Gentofte, Denmark; J. Eriksson, Q. Qiao, J. Tuomilehto, Department of Epidemiology and Health Promotion, National Public Health Institute, Helsinki.

Data analysis: G. Hu, Q. Qiao, Department of Epidemiology and Health Promotion, National Public Health Institute,
Helsinki, Finland; B. Balkau, INSERM U258-IFR69, Paris, France.

Writing Committee: B. Balkau, INSERM U258-IFR69, Paris, France; G. Hu, Q. Qiao, J. Tuomilehto, Diabetes and Genetic Epidemiology Unit, Department of Epidemiology and Health Promotion, National Public Health Institute, Helsinki, and Department of Public Health, University of Helsinki, Finland; K. Borch-Johnsen, Steno Diabetes Center, Gentofte, Denmark; K. Pyörälä, University of Kuopio, Kupopio, Finland

\section{References}

1. De Backer G, Ambrosioni E, Borch-Johnsen $\mathrm{K}$ et al. (2003) European guidelines on cardiovascular disease prevention in clinical practice: Third Joint Task Force of European and other Societies on Cardiovascular Disease Prevention in Clinical Practice. Eur J Cardiovasc Prev Rehabil 10:S1-S10

2. Grundy SM, Balady GJ, Criqui MH et al. (1988) Primary prevention of coronary heart disease: guidance from Framingham: a statement for healthcare professionals from the AHA Task Force on Risk Reduction. American Heart Association. Circulation 97:1876-1887

3. Jackson R (2000) Guidelines on preventing cardiovascular disease in clinical practice. BMJ 320:659-661

4. Grundy SM, D’ Agostino RB Sr, Mosca L et al. (2001) Cardiovascular risk assessment based on US cohort studies: findings from a National Heart, Lung, and Blood Institute workshop. Circulation 104:491-496

5. Kannel WB, Castelli WP, McNamara PM (1967) The coronary profile: 12-year follow-up in the Framingham Study. J Occup Med 9:611-619

6. Gordon T, Kannel WB (1982) Multiple risk functions for predicting coronary heart disease: the concept, accuracy, and application. Am Heart J 103:1031-1039

7. Anderson KM, Wilson PWF, Odell PM, Kannel WB (1991) An updated coronary risk profile. A statement for health professionals. Circulation 83:356-362

8. Wilson PWF, D'Agostino RB, Levy D, Belanger AM, Silbershatz H, Kannel WB (1998) Prediction of coronary heart disease using risk factor categories. Circulation 97: 1837-1847

9. ERICA Research Group (1991) Prediction of coronary heart disease in Europe. The 2nd report of the WHO-ERICA Project. Eur Heart J 12:291-297

10. Tunstall-Pedoe H (1991) The Dundee coronary risk-disk for management of change in risk factors. BMJ 303: 744-747

11. Knuiman, MW, Vu HTV (1997) Prediction of coronary heart disease mortality in Busselton, Western Australia: an evaluation of the Framingham, national health epidemiologic follow up study, and WHO ERICA risk scores. J Epidemiol Community Health 51:515-519

12. Pocock SJ, McCormack V, Gueyffier F, Boutitie F, Fagard $\mathrm{RH}$, Boissel J-P on behalf of the INDANA project steering committee (2001) A score for predicting risk of death from cardiovascular disease in adults with raised blood pressure, based on individual patient data from randomized controlled trials. BMJ 323:75-81

13. Assmann G, Cullen P, Schulte H (2002) Simple scoring scheme for calculating the risk of acute coronary events based on the 10-year follow-up of the prospective cardiovascular Munster (PROCAM) Study. Circulation 105:310- 315 
14. Glynn RJ, L'Italien GJ, Sesso HD, Jackson EA, Buring JE (2002) Development of predictive models for long-term cardiovascular risk associated with systolic and diastolic blood pressure. Hypertension 39:105-110

15. Thomsen TF, McGee D, Davidsen M, Jorgensen T (2002) A cross-validation of risk-scores for coronary heart disease mortality based on data from the Glostrup Population Studies and Framingham Heart Study. Int J Epidemiol 31: $817-822$

16. Chambless LE, Folsom AR, Sharrett AR et al. (2003) Coronary heart disease risk prediction in the Atherosclerosis Risk in Communities (ARIC) study. J Clin Epidemiol 56:880-889

17. Conroy RM, Pyörälä K, Fitzgerald AP et al. and the SCORE project group (2003) Estimation of ten-year risk of fatal cardiovascular disease in Europe: the SCORE project. Eur Heart J 24:987-1003

18. Haq IU, Ramsay LE, Yeo WW, Jackson PR, Wallis EJ (1998) Is the Framingham risk function valid for northern European populations? A comparison of methods for estimating absolute coronary risk in high risk men. Heart 81: 40-46

19. D'Agostino RB Sr, Grundy S, Sullivan LM, Wilson P for the CHD Risk Prevention Group (2001) Validation of the Framingham coronary heart disease prediction scores: results of a multiple ethnic groups investigation. JAMA 286: 180-187

20. Game FL, Jones AF (2001) Coronary heart disease risk assessment in diabetes mellitus - a comparison of PROCAM and Framingham risk assessment functions. Diabet Med 18:355-359

21. Bastuji-Garin S, Deverly A, Moyse D et al. on behalf of the INSIGHT committees and investigators (2002) The Framingham prediction rule is not valid in a European population of treated hypertensive patients. J Hypertens 20: 1973-1980

22. Cappuccio FP, Oakeshott P, Strazzullo P, Kerry SM (2002) Application of Framingham risk estimates to ethnic minorities in United Kingdom and implications for primary prevention of heart disease in general practice: cross sectional population based study. BMJ 325:1271-1274

23. Hense HW, Schulte H, Lôwel H, Assmann G, Keil U (2003) Framingham risk function overestimates risk of coronary heart disease in men and women from Germanyresults from the MONICA Augsburg and the PROCAM cohorts. Eur Heart J 24:937-945

24. Empana JP, Ducimetière P, Arveiler D et al. on behalf of the PRIME Study Group (2003) Are the Framingham and PROCAM coronary heart disease risk functions applicable to different European populations? The PRIME Study. Eur Heart J 24:1903-1911

25. The DECODE Study Group on behalf of the European Diabetes Epidemiology Group (1999) Glucose tolerance and mortality: comparison of WHO and American Diabetes Association diagnostic criteria. Lancet 354:617-621

26. The DECODE Study Group on behalf of the European Diabetes Epidemiology Group (2001) Glucose tolerance and cardiovascular mortality: comparison of fasting and 2-hour diagnostic criteria. Arch Intern Med 161:397-405

27. Balkau B, Shipley M, Jarrett RJ et al. (1998) High blood glucose concentration is a risk factor for mortality in middle-aged nondiabetic men. 20-year follow-up in the White- hall Study, the Paris Prospective Study, and the Helsinki Policemen Study. Diabetes Care 21:360-367

28. Balkau B, Bertrais S, Ducimetière P, Eschwège E (1999) Is there a glycaemic threshold for mortality risk? Diabetes Care 22:696-699

29. Coutinho M, Gerstein HC, Wang Y, Yusuf S (1999) The relationship between glucose and incident cardiovascular events. A metaregression analysis of published data from 20 studies of 95,783 individuals followed for 12.4 years. Diabetes Care 22:233-240

30. de Vegt F, Dekker JM, Ruhe HG et al. (1999) Hyperglycaemia is associated with all-cause and cardiovascular mortality in the Hoorn population: the Hoorn Study. Diabetologia 42:926-931

31. The DECODE Study Group (2003) Is the current definition for diabetes relevant to mortality risk from all causes and cardiovascular and noncardiovascular diseases? Diabetes Care 26:688-696

32. World Health Organization (1977) International classification of diseases, injuries and causes of death, revision 9. WHO, Geneva

33. World Health Organization (1993) International classification of diseases, injuries and causes of death, revision 10. WHO, Geneva

34. DECODE Study Group (2003) Gender difference in allcause and cardiovascular mortality related to hyperglycaemia and newly-diagnosed diabetes. Diabetologia 46: 608-617

35. World Health Organization Consultation (1999) Definition, diagnosis and classification of diabetes mellitus and its complications. Part 1: Diagnosis and classification of diabetes mellitus. Report of a WHO Consultation, WHO, Geneva

36. World Health Organization Mortality Data Base. Available from http://www.who.int/whosis

37. Stevens RJ, Kothari V, Adler AI, Stratton IM, United Kingdom Prospective Diabetes Study (UKPDS) Group (2001) The UKPDS risk engine: a model for the risk of coronary heart disease in Type II diabetes (UKPDS 56). Clin Sci (Lond) 101:671-679

38. Kothari V, Stevens RJ, Adler AI et al. (2002) UKPDS 60: risk of stroke in type 2 diabetes estimated by the UK Prospective Diabetes Study risk engine. Stroke 33:17761781

39. Ridker PM, Rifai N, Rose L, Buring JE, Cook NR (2002) Comparison of C-reactive protein and low-density lipoprotein cholesterol levels in the prediction of first cardiovascular events. N Engl J Med 347:1557-1565

40. Lind P, Hedblad B, Stavenow L, Janzon L, Eriksson KF, Lindgarde F (2001) Influence of plasma fibrinogen levels on the incidence of myocardial infarction and death is modified by other inflammation-sensitive proteins: a longterm cohort study. Arterioscler Thromb Vasc Biol 21:452458

41. Gerstein HC, Mann JF, Yi Q et al. for the HOPE Study Investigators (2001) Albuminuria and risk of cardiovascular events, death, and heart failure in diabetic and nondiabetic individuals. JAMA 286:421-426

42. Hall LM, Jung RT, Leese GP (2003) Controlled trial of effect of documented cardiovascular risk scores on prescribing. BMJ 326:251-252 